\title{
ESTABILIDADE DA SÍLICA BIOGÊNICA EXTRAÍDA DE CAPIM JARAGUÁ (Hyparrhenia rufa) EM SOLUÇÃO DE NaOH
}

\author{
Liovando M. Costa \\ Departamento de Solos, Universidade Federal de Viçosa , 36571-000 Viçosa - MG, Brasil \\ Ana Maria S. S. Moreau* e Mauricio S. Moreau \\ Departamento de Ciências Agrárias e Ambientais, Universidade Estadual de Santa Cruz, Rodovia Ilhéus - Itabuna, km 16, \\ 45650-000 Ilhéus - BA, Brasil
}

Recebido em 29/10/09; aceito em 20/5/10; publicado na web em 17/9/10

\begin{abstract}
STABILITY OF BIOGENIC SILICA EXTRACT OF JARAGUÁ GRASS (Hyparrhenia rufa) IN NaOH SOLUTION. Biogenic silica is used to describe compounds of hydrated silica $\left(\mathrm{SiO}_{2} \cdot \mathrm{nH}_{2} \mathrm{O}\right)$, with specific shapes and sizes, deposited in plants. The chemical composition of biogenic silica and its stability in Jaraguá grass was studied in increasing concentration of $\mathrm{NaOH}$. The analytical results demonstrated high concentration of $\mathrm{Si}, \mathrm{Al}, \mathrm{Fe}, \mathrm{Mg}, \mathrm{P}$ and low of $\mathrm{Cu}, \mathrm{Cd}$ and $\mathrm{Zn}$ in the phytoliths composition. The silica bodies stability in $\mathrm{NaOH}$ solution with increasing concentration was different among the shapes and sizes. Silicified stomata and silicified plant tissues were dissolved along with the dumbbells because they are the less stable forms of biogenic silica.
\end{abstract}

Keywords: phytoliths; silica bodies; Poaceae.

\section{INTRODUÇÃO}

A crosta terrestre possui $27,7 \%$ de silício em massa em sua composição e os solos possuem, em média, $32 \%$ de $\mathrm{Si}$, predominantemente na forma de minerais silicatados, primários ou secundários. ${ }^{1,2}$ Apesar de o silício ser o segundo elemento mais abundante na crosta terrestre, sua contribuição na composição química dos organismos é relativamente pequena, enquanto o carbono, quimicamente muito semelhante ao silício, mas cuja abundância é muitíssimo menor, é o principal componente dos seres vivos. ${ }^{3,4}$

Apesar de estar presente em concentrações não desprezíveis nos tecidos vegetais o Si não é considerado, pela grande maioria dos fisiologistas, como um elemento essencial na nutrição de plantas superiores. Epstein ${ }^{5,6}$ defende a essencialidade do silício para algumas espécies vegetais e propõe que, para a maioria, o elemento seria no mínimo benéfico, partindo das observações de que o silício é praticamente onipresente nos vegetais e, em geral, as concentrações de Si são maiores do que as de macronutrientes. Trabalhos como os de Martinez Angel et al. ${ }^{7}$ atestam a essencialidade do silício ao demonstrarem a viabilidade técnica de valorizar um resíduo como a casca de arroz, pela obtenção de cinza com altos teores de sílica amorfa (>93\%) e baixos teores de carbono (perda ao fogo inferior a $3 \%$ ).

O quartzo, apesar de ser a forma mais abundante de silício na crosta terrestre, não se constitui numa fonte apreciável de ácido monossilícico para a biota, pois a taxa de intemperização do mesmo é muito baixa. ${ }^{8}$

Nesse sentido, organismos como diatomáceas, esponjas e vegetais superiores teriam um papel relevante no ciclo biogeoquímico do silício, apesar da ênfase maior ser dada à renovação do silício na crosta terrestre via sub-ducção do assoalho oceânico e formação de montanhas, o que requer dezenas ou centenas de milhões de anos.

Não obstante, a acumulação de Si nas plantas é suficiente para afetar a disponibilidade da sílica em solução. Na selva do Congo, na África, 74\% do Si solúvel se originou da dissolução de fitólitos. Numa ilha vulcânica do Oceano Índico, registrou-se uma camada de $15 \mathrm{~cm}$ de espessura de fitólitos e a acumulação foi favorecida pela presença do bambu e de Si disponível nas cinzas vulcânicas. ${ }^{9}$

\footnotetext{
*e-mail: amoreau@uesc.br
}

A questão da dissolução diferencial de morfotipos diversos de fitólitos é relevante não só para a compreensão do balanço de silício na solução do solo, mas também para interpretação da dinâmica de deposição e movimentação dos fitólitos no solo, ${ }^{10}$ de deposição de sedimentos, ${ }^{11}$ de formação de paleossolos e para análise de sítios arqueológicos. Assim como pólen e esporos, fitólitos fósseis são usados como representativos de antigas formas de vegetação nas pesquisas sobre o Quaternário. ${ }^{12}$

Carnelli et al. ${ }^{13}$ analisaram fitólitos de monocotiledôneas, dicotiledôneas e coníferas dos Alpes suíços, detectando, a partir de análises semiquantitativas, virtual ausência de Al em fitólitos de monocotiledôneas, enquanto em fitólitos de folhas de dicotiledôneas e coníferas a presença de $\mathrm{Al}$ foi comum. Os autores sugerem que a variabilidade nos teores de $\mathrm{Al}$ entre grupos vegetais pode auxiliar na análise de assembleias de fitólitos indicadores de paleoambientes, visto que a maior resistência à dissolução de certos tipos morfológicos, que seriam diferencialmente preservados, levaria a um enriquecimento gradual destes fitólitos nos horizontes mais profundos de solos não perturbados, como observado por Alexandre et al. ${ }^{10}$

Sabe-se que o teor de Si nas plantas e a concentração de Si solúvel na solução do solo são interdependentes. Quais seriam então os efeitos da aplicação de adubos silicatados sobre a solubilidade de fitólitos? A produção de fitólitos mais susceptíveis à dissolução mais lábeis, nas palavras de Alexandre et al., ${ }^{10}$ pode ser uma resposta evolutiva a uma pressão ambiental, talvez escassez de Si (em Latossolos, por exemplo). A adição de adubos ricos em Si ao solo poderia influenciar as condições de formação dos fitólitos nas plantas, quiçá aumentando as concentrações de fitólitos menos solúveis.

Entretanto, a diminuição da solubilidade de fitólitos no solo pode ser desejável, por exemplo, visando aumentar a durabilidade da proteção dos compostos orgânicos oclusos nos corpos silicosos. Avaliando a contribuição do carbono ocluso em fitólitos para o carbono orgânico total do solo em Paleossolos, Parr e Sullivan ${ }^{14}$ detectaram aumento na relação $\mathrm{C}$ fitólitos/C total com a idade dos estratos, sugerindo que a sílica biogênica confere ao carbono proteção contra a degradação microbiana por um período longo. Esta proteção pode ser quantitativamente maximizada pela otimização dos fatores que afetam a produção de fitólitos pelas plantas. 
Apesar da relevância do tema e das inúmeras aplicações, a estabilidade da sílica biogênica não tem sido estudada adequadamente por pesquisadores que se dedicam às biomineralizações. A biogeoquímica do silício pode beneficiar-se muito com as informações que podem ser obtidas nos estudos de estabilidade da sílica biogênica.

São muitos escassos os relatos de metodologias visando analisar a dissolução diferencial de diferentes morfologias de fitólitos. As formas mais estáveis de fitólitos podem funcionar como marcadores de mudanças climáticas e de vegetação em estudos do Quaternário e permitem, ainda, estudar a distribuição de plantas nativas ou cultivadas de importância ambiental e econômica em determinada área. Além disto, como já abordado, a constatação da dissolução diferencial de diferentes morfotipos de corpos silicosos pode auxiliar no entendimento da contribuição da sílica biogênica no ciclo biogeoquímico do silício.

\section{PARTE EXPERIMENTAL}

Foi selecionada a gramínea forrageira Jaraguá (Hyparrhenia rufa) pela variedade de fitólitos produzidos por ela, sendo encontrados os halteres, os bastonetes lisos e serrilhados, tricomas, os estômatos e tecidos silicificados..$^{15-17} \mathrm{O}$ material foi coletado em talude de tufito na BR 365, município de Patos de Minas, MG (coordenadas $18^{\circ} 38^{\prime}$ $04^{\prime \prime}$ sul e $46^{\circ} 21^{\prime}$ '44" oeste).

Após a lavagem inicial com água de torneira para remoção de impurezas, separaram-se as folhas para extração dos fitólitos. As amostras do material vegetal foram então enxaguadas com água destilada e deionizada, secas ao ar e depois cortadas em pedaços de aproximadamente $2 \mathrm{~cm}$. A seguir, a biomassa fragmentada foi colocada em cadinhos de porcelana e levada à mufla regulada a 500 $\pm 5^{\circ} \mathrm{C}$ por $5 \mathrm{~h}$. Nesse binômio tempo-temperatura, a parte orgânica é transformada em gás carbônico, vapor de água e energia, sobrando as cinzas. Essas são constituídas de fitólitos, carvão e alguns elementos químicos contidos na biomassa queimada. O que realmente interessa são os fitólitos, facilmente identificados por observação microscópica.

Após esse procedimento, amostras de $500 \mathrm{mg}$ das cinzas foram pesadas com precisão analítica e submetidas a tratamento com $40 \mathrm{~mL}$ de $\mathrm{HCl} 0,5 \mathrm{~mol} \mathrm{~L}^{-1}$ por $4 \mathrm{~h}$. $\mathrm{O}$ uso deste ácido na referida concentração objetivou extrair das cinzas os elementos químicos que não constituem os fitólitos propriamente, ou seja, o material pulverizado que não pode ser identificado ao microscópio ótico. Dos ácidos comumente utilizados em laboratório, como $\mathrm{HCl}$, $\mathrm{HNO}_{3}$ e $_{2} \mathrm{SO}_{4}$, optou-se pelo $\mathrm{HCl}$ pela alta solubilidade dos cloretos a partir das cinzas. Apesar do $\mathrm{HNO}_{3}$ também formar sais muito solúveis, o $\mathrm{HCl}$ é mais barato e, em função dos resultados obtidos, foi o ácido selecionado para este trabalho.

Após filtragem, nos extratos obtidos foram determinados $\mathrm{Ca}, \mathrm{Mg}$, $\mathrm{P}, \mathrm{Si}, \mathrm{Al}, \mathrm{Fe}, \mathrm{Mn}, \mathrm{Zn}, \mathrm{Ni}, \mathrm{Cu}, \mathrm{Cd}$, As, $\mathrm{Cr}$ e $\mathrm{Pb}$, por espectrometria de emissão óptica com plasma indutivamente acoplado (ICP OES), marca PerkinElmer modelo Optima 3300 DV.

O resíduo desse tratamento constitui-se de fitólitos e para o estudo da estabilidade da sílica biogênica, $250 \mathrm{mg}$ desse material, pesado com precisão analítica, permaneceu em contato por $6 \mathrm{~h}$, com agitações de 20 em 20 min, com $\mathrm{NaOH}$ nas concentrações de 0,50; 1,00; 1,50 e 2,00 $\mathrm{mol} \mathrm{L}^{-1}$. Esse procedimento foi realizado na temperatura de $25^{\circ} \mathrm{C}$ e em banho-maria a $90{ }^{\circ} \mathrm{C}$, com três repetições para cada concentração. Após o período de $6 \mathrm{~h}$, filtrou-se o sobrenadante e nos extratos obtidos foram determinados por ICP OES os elementos $\mathrm{Si}$, $\mathrm{Al}, \mathrm{Fe}, \mathrm{Mg}, \mathrm{P}, \mathrm{Cu}, \mathrm{Cd}, \mathrm{Zn}, \mathrm{Se}, \mathrm{Cr}, \mathrm{Pb}, \mathrm{Mn}, \mathrm{Ni}, \mathrm{Ca}$ e As.

Após cada dissolução, sub-amostras dos resíduos foram preparadas em lâminas e observadas ao microscópio ótico para avaliação do comportamento de dissolução dos corpos silicosos. Utilizou-se microscópio óptico Olympus CX31 (com aumentos de 100 e 400 vezes). Assim se pode acompanhar o processo de desgaste dos diferentes corpos silicosos por meio das microfotografias, para registro da dissolução mediante adição crescente de hidróxido de sódio à sílica biogênica.

\section{RESULTADOS E DISCUSSÃO}

Na Tabela 1 encontram-se os resultados referentes aos teores dos elementos químicos presentes na cinza do capim Jaraguá, extraídos com $\mathrm{HCl} 0,5 \mathrm{~mol} \mathrm{~L}^{-1}$. Os resultados revelam que os principais constituintes da cinza são $\mathrm{Ca}, \mathrm{Mg}, \mathrm{P}, \mathrm{Si}, \mathrm{Al}$ e $\mathrm{Fe}$. Apesar do baixo teor do silício obtido com $\mathrm{HCl}$, as amostras de capim Jaraguá quando tratadas com $\mathrm{NaOH} 0,5 \mathrm{~mol} \mathrm{~L}^{-1}$ a $25^{\circ} \mathrm{C}$ apresentaram um aumento de 61 vezes no teor de Si e de 132 vezes a $90{ }^{\circ} \mathrm{C}$, com a menor concentração do hidróxido.

Tabela 1. Análise química do extrato obtido após tratamento da cinza do capim Jaraguá com $\mathrm{HCl} 0,5 \mathrm{~mol} / \mathrm{L}$

\begin{tabular}{ccc}
\hline Elemento & \multicolumn{2}{c}{ Teores no extrato } \\
& $\mathrm{mg} / \mathrm{kg}$ & $\%$ \\
$\mathrm{Ca}$ & 13223,69 & 1,32 \\
$\mathrm{Mg}$ & 7906,36 & 0,79 \\
$\mathrm{P}$ & 5923,37 & 0,59 \\
$\mathrm{Si}$ & 3328,82 & 0,33 \\
$\mathrm{Al}$ & 572,44 & 0,057 \\
$\mathrm{Fe}$ & 503,40 & 0,050 \\
$\mathrm{Mn}$ & 153,73 & 0,0153 \\
$\mathrm{Zn}$ & 52,64 & 0,0052 \\
$\mathrm{Ni}$ & 29,10 & 0,0029 \\
$\mathrm{Cu}$ & 16,02 & 0,0016 \\
$\mathrm{Cd}$ & 6,45 & 0,00065 \\
$\mathrm{As}$ & 2,49 & 0,00025 \\
$\mathrm{Cr}$ & 0,54 & 0,000054 \\
$\mathrm{~Pb}$ & 0,50 & 0,000050 \\
\hline
\end{tabular}

Segundo Korndörfer et al., ${ }^{18}$ os teores totais de Si na planta são classificados como baixos quando menores que $17000 \mathrm{mg} \mathrm{kg}^{-1}$; médios, de 17000 a $34000 \mathrm{mg} \mathrm{kg}^{-1} \mathrm{e}$ altos acima de $34000 \mathrm{mg} \mathrm{kg}^{-1}$.

Na Tabela 2 nota-se que os teores de Si nos fitólitos são altos e a temperatura teve um efeito marcante na concentração do silício dissolvido, que passou de 203216 para $439488 \mathrm{mg} \mathrm{kg}^{-1}$ quando a temperatura de reação do $\mathrm{NaOH} 0,5 \mathrm{~mol} / \mathrm{L}$ passou de 25 para $90{ }^{\circ} \mathrm{C}$, ou seja 2,1 vezes maior. Com o aumento da concentração da base, o pH aumenta, mas não consegue manter a concentração de Si em solução. Os teores de $\mathrm{Si}$ recuperados nos tratamentos à temperatura de $90{ }^{\circ} \mathrm{C}$ são maiores que os obtidos a $25^{\circ} \mathrm{C}$, no entanto, a tendência foi de diminuírem com o aumento da concentração de hidróxido de sódio. Tudo indica que a $90{ }^{\circ} \mathrm{C}$ parte do $\mathrm{Si}$ se polimeriza, por isso, a concentração relativa decresce $6 \%$ e a $25^{\circ} \mathrm{C}$ o acréscimo é de $18 \%$, comparados com a concentração de $0,5 \mathrm{~mol} / \mathrm{L}$. Na maior concentração do $\mathrm{NaOH}$ houve redução de $26 \%$ no teor de Si. Desse modo, a concentração do $\mathrm{Si}$ em solução atingiu o ponto máximo, 43,9\%, quando a concentração do hidróxido foi de $0,5 \mathrm{~mol} / \mathrm{L}$.

Na temperatura de $25{ }^{\circ} \mathrm{C}$ ocorre aumento de $\mathrm{Si}$ em solução na medida que a concentração do $\mathrm{NaOH}$ aumenta. Além disso, a concentração de Si em solução aumentou $30 \%$ da primeira para a última concentração da base. Não ocorreu concentração máxima do Si no intervalo de 0,5 a 2,0 mol/L de $\mathrm{NaOH}$. A partir dos dados da Tabela 
Tabela 2. Teores de silício dos fitólitos do capim Jaraguá extraídos com quatro concentrações de hidróxido de sódio às temperaturas de 90 e $25^{\circ} \mathrm{C}$

\begin{tabular}{ccccccc}
\hline $\begin{array}{c}\text { Conc. } \\
\mathrm{NaOH} \mathrm{mol} / \mathrm{L}\end{array}$ & $\begin{array}{c}\mathrm{Si}^{(1)} \\
\mathrm{mg} / \mathrm{kg}\end{array}$ & $\begin{array}{c}\mathrm{Si}^{(1)} \\
\%\end{array}$ & Conc. Rel. & $\begin{array}{c}\mathrm{Si}^{(2)} \\
\mathrm{mg} / \mathrm{kg}\end{array}$ & $\begin{array}{c}\mathrm{Si}^{(2)} \\
\%\end{array}$ & Conc. Rel. \\
\hline 0,5 & 439488,0 & 43,9 & 100 & 203216 & 20,3 & 100 \\
1,0 & 411425,3 & 41,1 & 94 & 240426 & 24,0 & 118 \\
1,5 & 353798,0 & 35,4 & 81 & 253756 & 25,4 & 125 \\
2,0 & 326825,3 & 32,7 & 74 & 264974 & 26,5 & 130 \\
\hline
\end{tabular}

(1) Temperatura $90^{\circ}$; (2) Temperatura $25^{\circ} \mathrm{C}$

2, pode-se calcular a relação do $\mathrm{Si}^{(1)}$, temperatura $90^{\circ} \mathrm{C}$, para $\mathrm{Si}^{(2)}$, a $25^{\circ} \mathrm{C}$, e seus valores são de 2,$2 ; 1,7 ; 1,4$ e 1,2 vezes da menor para a maior concentração do hidróxido de sódio.

A concentração relativa do silício contido nos fitólitos, para a temperatura de $25^{\circ} \mathrm{C}$, variou de 100 a 130 (Tabela 2). A concentração média de Si foi de $38,3 \%$ quando a dissolução foi realizada à $90{ }^{\circ} \mathrm{C}$, nas quatro concentrações de hidróxido e de $24,1 \%$ à temperatura de $25^{\circ} \mathrm{C}$.

A composição dos fitólitos é governada pela disponibilidade dos elementos na solução do solo e pelos resultados dos tratamentos com hidróxido de sódio (Tabelas 3 e 4); os fitólitos do capim Jaraguá contêm quantidades consideráveis de $\mathrm{Si}, \mathrm{Al}, \mathrm{Fe}, \mathrm{Mg}$ e $\mathrm{P}$, além de concentrações menores de $\mathrm{Cu}, \mathrm{Cd}$ e $\mathrm{Zn}$.

Como alguns autores sugerem, o conteúdo total de qualquer elemento no material de origem reflete no seu conteúdo no solo. ${ }^{19-21}$ Aumentos nas concentrações de metais no solo podem refletir em aumento na disponibilidade às plantas; entretanto, diversos fatores afetam a biodisponibilidade de metais. Nesse particular, é importante destacar que a amostra de capim Jaraguá utilizada no presente estudo foi coletada em cima de tufito, sendo este um material piroclástico resultante de atividade vulcânica, cuja composição química pode apresentar teores consideráveis de $\mathrm{P}, \mathrm{Ca}, \mathrm{Mg}$ e $\mathrm{K}$ e alguns elementos traços, com destaque para o $\mathrm{Cr}, \mathrm{Cu}, \mathrm{Ni}$ e $\mathrm{Zn} .{ }^{22}$ Assim, a constituição química dos fitólitos pode ser indicadora da constituição química do solo e das rochas, especialmente em solos jovens.

As médias das concentrações de $\mathrm{Cu}, \mathrm{Cd}$ e $\mathrm{Zn}$ estão entre 2 e 9 $\mathrm{mg} \mathrm{kg}^{-1}$. Considerando-se apenas a concentração, espera-se que haja pouca influência deles na estabilidade dos fitólitos.

A abundância desses elementos na crosta terrestre, em $\mathrm{mg} \mathrm{kg}^{-1}$, é: $\mathrm{Cu}(55), \mathrm{Cd}(0,2)$ e $\mathrm{Zn}(110) .{ }^{23} \mathrm{O}$ valor do $\mathrm{Cd}$ encontrado na dissolução dos fitólitos é de $3,9 \mathrm{mg} / \mathrm{kg}$ a $25^{\circ} \mathrm{C}$ e de 3,1 a $90^{\circ} \mathrm{C}$, portanto, 17,5 vezes maior do que o valor encontrado na crosta terrestre. Esse elemento é considerado cancerígeno para o homem ${ }^{24,25}$ e deve ser tóxico para os micro-organismos. ${ }^{26} \mathrm{~A}$ atividade microbiana pode ser comprometida no ambiente onde esteja ocorrendo dissolução com a participação microbiana. ${ }^{8}$ Além disso, segundo Baker e Chesnin, ${ }^{27}$ teores acima de $0,2 \mathrm{mg} \mathrm{kg}^{-1}$ de cádmio nas plantas já são considerados tóxicos e prejudiciais ao seu desenvolvimento.

A afinidade geoquímica entre $\mathrm{Cu}$ e $\mathrm{Zn}$, em razão da similaridade quanto ao raio iônico e eletropositividade, explica sua ocorrência associada. ${ }^{28}$ Os fitólitos podem ocluir metais traços em seu interior. Esse mecanismo ajuda a reduzir a toxicidade de alguns metais nas plantas.

Foram preparadas várias lâminas dos corpos silicosos das folhas do Jaraguá para o estudo de estabilidade da sílica biogênica. Nesta gramínea são encontrados os halteres, os bastonetes lisos e serrilhados, tricomas, os estômatos e tecidos silicificados (Figura 1a e b).

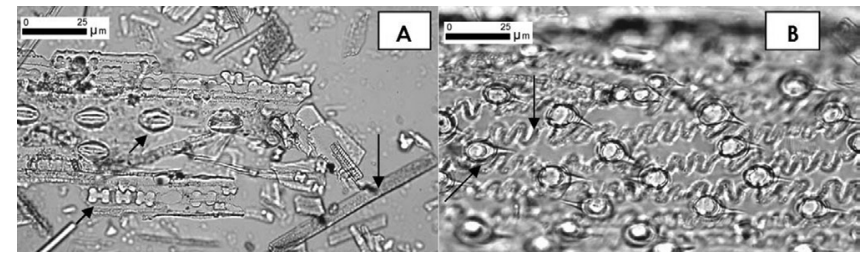

Figura 1. Fitólitos das cinzas de Jaraguá(Hyparrhenia rufa) tratada com $\mathrm{HCl}$ 0,5 mol/L. (A) Organização das estruturas silicificadas, halteres, estômatos silicificados e bastonetes; (B) tricomas em tecido silicificado

A avaliação do comportamento de dissolução dos corpos silicosos, ao microscópio óptico, revelou que os fitólitos de formas e

Tabela 3. Análise química dos extratos de dissolução do capim Jaraguá com quatro concentrações de hidróxido de sódio à temperatura ambiente $\left(25^{\circ} \mathrm{C}\right)$

\begin{tabular}{|c|c|c|c|c|c|c|c|}
\hline \multirow[t]{2}{*}{ Elementos } & \multicolumn{4}{|c|}{$\begin{array}{l}\text { Tratamentos } \mathrm{NaOH}(\mathrm{mol} / \mathrm{L}) \\
\text { (Média de três repetições) }\end{array}$} & \multirow[t]{3}{*}{$\begin{array}{c}\text { Média } \\
\text { Tratamentos }\end{array}$} & \multirow[t]{3}{*}{$\begin{array}{l}\text { Desvio } \\
\text { Padrão }\end{array}$} & \multirow{3}{*}{$\begin{array}{c}\text { Coeficiente de } \\
\text { Variação } \\
\%\end{array}$} \\
\hline & \multirow[t]{2}{*}{0,5} & 1,0 & 1,5 & \multirow[t]{2}{*}{2,0} & & & \\
\hline & & 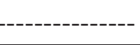 & ------------ & & & & \\
\hline $\mathrm{Si}$ & 203216,00 & 240426,00 & 253756,00 & 264974,00 & 240593,00 & 23263,52 & 9,67 \\
\hline $\mathrm{Al}$ & 69,20 & 102,96 & 121,96 & 128,20 & 105,58 & 22,97 & 21,75 \\
\hline $\mathrm{Fe}$ & 106,88 & 103,64 & 137,36 & 115,20 & 115,77 & 13,16 & 11,37 \\
\hline $\mathrm{Mg}$ & 97,52 & 124,12 & 158,88 & 165,76 & 136,57 & 27,52 & 20,15 \\
\hline $\mathrm{P}$ & 52,16 & 45,44 & 38,04 & 38,60 & 43,56 & 5,76 & 13,21 \\
\hline $\mathrm{Cu}$ & 8,92 & 8,36 & 7,52 & 8,48 & 8,32 & 0,51 & 6,09 \\
\hline $\mathrm{Cd}$ & 4,16 & 3,88 & 3,76 & 3,72 & 3,88 & 0,17 & 4,43 \\
\hline $\mathrm{Zn}$ & 0,08 & 1,68 & 3,08 & 4,24 & 2,27 & 1,55 & 68,53 \\
\hline $\mathrm{Se}$ & 4,44 & 0,0 & 0,0 & 0,0 & 1,11 & 1,92 & 173,20 \\
\hline $\mathrm{Cr}$ & 0,0 & 0,0 & 0,0 & 0,0 & 0,0 & 0,0 & 0,0 \\
\hline $\mathrm{Pb}$ & 0,0 & 0,0 & 0,0 & 0,0 & 0,0 & 0,0 & 0,0 \\
\hline $\mathrm{Mn}$ & 0,0 & 0,0 & 0,0 & 0,0 & 0,0 & 0,0 & 0,0 \\
\hline $\mathrm{Ni}$ & 0,0 & 0,0 & 0,0 & 0,0 & 0,0 & 0,0 & 0,0 \\
\hline $\mathrm{Ca}$ & 0,0 & 0,0 & 0,0 & 0,0 & 0,0 & 0,0 & 0,0 \\
\hline As & 0,0 & 0,0 & 0,0 & 0,0 & 0,0 & 0,0 & 0,0 \\
\hline
\end{tabular}


Tabela 4. Análise química dos extratos de dissolução do capim Jaraguá com quatro concentrações de hidróxido de sódio a 90 C

\begin{tabular}{|c|c|c|c|c|c|c|c|}
\hline \multirow[t]{3}{*}{ Elementos } & \multicolumn{4}{|c|}{$\begin{array}{l}\text { Tratamentos } \mathrm{NaOH}(\mathrm{mol} / \mathrm{L}) \\
\text { (Média de três repetições) }\end{array}$} & \multirow[t]{3}{*}{$\begin{array}{c}\text { Média } \\
\text { Tratamentos }\end{array}$} & \multirow[t]{3}{*}{$\begin{array}{l}\text { Desvio } \\
\text { Padrão }\end{array}$} & \multirow{3}{*}{$\begin{array}{c}\text { Coeficiente de } \\
\text { Variação } \\
\%\end{array}$} \\
\hline & \multirow[t]{2}{*}{0,5} & 1,0 & 1,5 & 2,0 & & & \\
\hline & & ------------ & ----------- & & & & \\
\hline $\mathrm{Si}$ & 439488,00 & 411425,33 & 353798,00 & 326825,30 & 382884,20 & 44741,46 & 11,68 \\
\hline $\mathrm{Al}$ & 219,47 & 226,83 & 280,68 & 377,89 & 276,22 & 63,28 & 22,91 \\
\hline $\mathrm{Fe}$ & 303,09 & 146,08 & 159,28 & 137,36 & 186,45 & 67,79 & 36,36 \\
\hline $\mathrm{Mg}$ & 286,88 & 51,01 & 21,24 & 15,79 & 93,73 & 112,32 & 119,83 \\
\hline $\mathrm{P}$ & 94,16 & 80,88 & 79,40 & 79,97 & 83,60 & 6,12 & 7,32 \\
\hline $\mathrm{Cu}$ & 9,68 & 8,27 & 8,60 & 7,47 & 8,50 & 0,79 & 9,33 \\
\hline $\mathrm{Cd}$ & 3,15 & 3,01 & 3,04 & 3,09 & 3,07 & 0,05 & 1,73 \\
\hline $\mathrm{Zn}$ & 6,72 & 6,00 & 8,12 & 7,52 & 7,09 & 0,80 & 11,31 \\
\hline $\mathrm{Ca}$ & 41,07 & 2,32 & 0,0 & 0,0 & 10,85 & 17,47 & 161,06 \\
\hline $\mathrm{Cr}$ & 0,0 & 0,0 & 0,0 & 0,0 & 0,0 & 0,0 & 0,0 \\
\hline $\mathrm{Pb}$ & 0,0 & 0,0 & 0,0 & 0,0 & 0,0 & 0,0 & 0,0 \\
\hline $\mathrm{Mn}$ & 0,0 & 0,0 & 0,0 & 0,0 & 0,0 & 0,0 & 0,0 \\
\hline $\mathrm{Ni}$ & 0,0 & 0,0 & 0,0 & 0,0 & 0,0 & 0,0 & 0,0 \\
\hline $\mathrm{Se}$ & 0,0 & 0,0 & 0,0 & 0,0 & 0,0 & 0,0 & 0,0 \\
\hline As & 0,0 & 0,0 & 0,0 & 0,0 & 0,0 & 0,0 & 0,0 \\
\hline
\end{tabular}

diferentes tamanhos postos em contato com o hidróxido de sódio não apresentaram a mesma reatividade com esse reagente, mesmo tendo sido formados na mesma planta e nas mesmas condições ambientais. Isso demonstra que eles têm estabilidades diferentes em meio básico.

Tanto os estômatos como os tecidos silicificados tendem a ser dissolvidos juntamente com os halteres. Os estômatos e os tecidos silicificados devem apresentar estabilidade semelhante. Observa-se ao microscópio (Figura 1a), que a silicificação ocorre nas paredes celulares dos tecidos silicificados. Nesse caso, a superfície de contato entre o hidróxido e as paredes celulares silicificadas é grande, o que facilita em muito a dissolução da sílica nessa parte dos tecidos.

Há uma organização natural da distribuição dos tecidos silicificados nas folhas das plantas (Figura 1a). Esse aspecto pode ser visto com facilidade nas fotos microscópicas obtidas nesta pesquisa. É inevitável a formação de pontos carbonizados nas cinzas, o que dá cor escura na massa queimada. Os fitólitos encontrados nas ilhas de material carbonizado parecem não reagir com o tratamento à base de hidróxido (Figura 2). As substâncias orgânicas, contidas no interior dos fitólitos, podem ser carbonizadas, o que confere cor escura a eles. Sabe-se que todo biomineral tem forma que é definida pelos compostos orgânicos que fazem parte de sua constituição química. É possível que o teor de carbono possa ser diferente dentro do mesmo tipo de sílica biogênica ou entre diferentes tipos. As formas de fitólitos são sintetizadas nos organismos vivos tendo por base uma matriz orgânica. Nas análises de fitólitos, o carbono orgânico é determinado no conjunto de diversos tipos de fitólitos contidos na amostra. Por outro lado, uma análise individual somente seria possível usando técnicas microquímicas.

Algumas plantas produzem cinzas muito claras e outras cinzas muito escuras, nesta última a queima foi incompleta com formação de partículas de carvão. Parece existir uma relação entre a concentração dos fitólitos com cor escura da cinza. A cor escura observada no interior de fitólitos pode ser uma evidência de transformação da matéria orgânica em carvão pela carbonização (Figura 2).

Os tecidos silicificados servem de suporte na distribuição dos diferentes fitólitos em cada planta. Esses tecidos juntamente com os fitólitos evitam o acamamento das plantas que os contêm. Desse

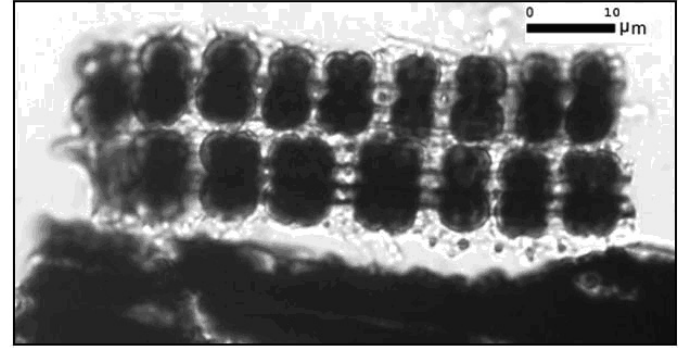

Figura 2. Presença de tecido carbonizado nas cinzas do capim Jaraguá (Hyparrhenia rufa) após tratamento com $\mathrm{NaOH}$

modo, o silício tem sido recomendado para evitar a quebra de plantas que sofrem esforços no sentido de quebrá-las. Sendo o Si um elemento estrutural, oferece rigidez às diversas partes das plantas, reduzindo a ruptura de partes das plantas submetidas aos ventos ou qualquer outro tipo de estresse mecânico.

Os tecidos silicificados permitem que pedaços de cinzas flutuem no ar e podem ser transportados a diferentes distâncias, em função da estabilidade dessa estrutura ou do arranjo natural dos componentes da sílica biogênica. Partículas de cinzas, normalmente de cor escura, de capim Jaraguá podem espalhar-se por uma considerável área a partir do ponto onde o capim é queimado. A referida organização começa a ser alterada à medida que a cinza entra em contato com os reagentes usados na remoção das impurezas ou na dissolução em meio básico. Nesse processo, os halteres do Jaraguá são retirados da estrutura original quando o $\mathrm{NaOH}$ rompe os pontos de ligação entre diferentes formas de sílica contidas na planta. Os fitólitos ficam assim individualizados à medida que a concentração do hidróxido aumenta, principalmente aqueles que dependem do suporte dos tecidos silicificados. A Figura 3 ilustra esse fato com muita propriedade.

A dissolução dos halteres foi mais ativa naqueles de tamanhos maiores (Figura 4). Assim, observou-se aumento na concentração relativa dos halteres menores. Esse é um resultado paradoxal, já que os halteres menores têm superfície específica maior, o que deveria 


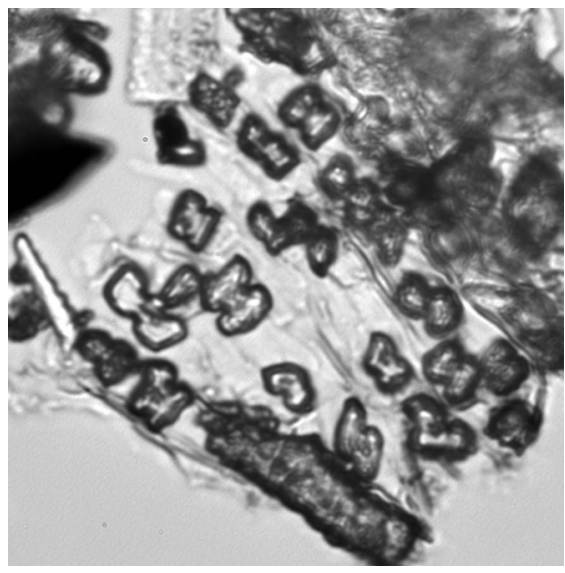

Figura 3. Tecido silicificado do capim Jaraguá (Hyparrhenia rufa), com a presença de fitólito do tipo halter dentro e fora dessa estrutura, após tratamento com $\mathrm{HCl} 0,5 \mathrm{~mol} / \mathrm{L}$

torná-los mais reativos, pois a superfície de contato entre o hidróxido e os fitólitos é maior. Isso mostra que o tamanho dos fitólitos não é a única característica importante na dissolução. Acredita-se que a composição química dos dois tamanhos de halteres possa dar alguma ajuda nesse sentido, no entanto, nas análises químicas, todos os fitólitos são analisados sem levar em conta os tipos e os tamanhos deles, pois, separá-los para serem analisados não é uma tarefa simples.

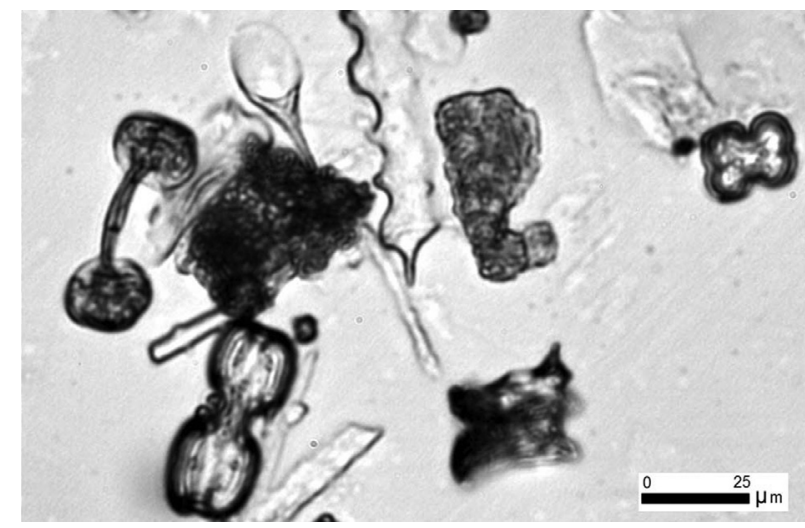

Figura 4. Dissolução dos fitólitos maiores do tipo halteres de capim Jaraguá (Hyparrhenia rufa), em tratamento com hidróxido de sódio 0,5 mol/L

O desgaste dos halteres inicia-se na concentração de hidróxido de sódio $0,5 \mathrm{~mol} / \mathrm{L}$ e progride para concentrações maiores, especialmente na sua cintura, onde sempre começa a dissolução (Figura 5), e nos tecidos e estômatos silicificados. Nos dois últimos não é possível observar os desgastes diretamente ao microscópio, como são vistos nos halteres. De qualquer forma, nota-se que as estruturas silicificadas começam a diminuir quando comparadas com a amostra que apenas teve contato com o único tratamento feito com o $\mathrm{HCl} \mathrm{0,5}$ $\mathrm{mol} / \mathrm{L}$ usado para remover as impurezas dos fitólitos (Figura 1). Além disso, as estruturas silicificadas começam a perder o poder de manter os fitólitos agregados a elas.

As fotos mostram que a dissolução é preferencial em pontos definidos dos fitólitos. No caso dos halteres, ela começa pela cintura do fitólito e avança em direção às suas extremidades. A dissolução é mais rápida e severa nos tratamentos em banho-maria a $90{ }^{\circ} \mathrm{C}$. Nestes, a dissolução ocorre mais na transversal do que na direção longitudinal, chegando à quebra da haste que liga as extremidades. Há uma visível deformação dos fitólitos quando a dissolução encontra-se em estágio avançado (Figura 6).

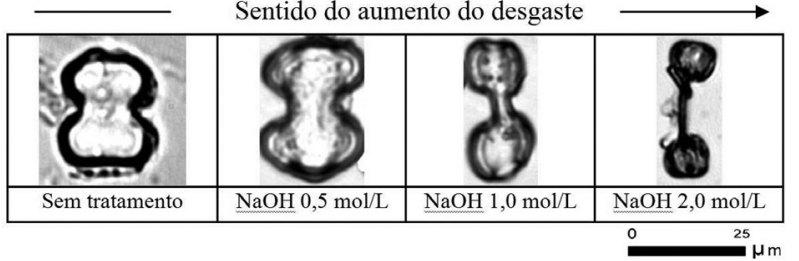

Figura 5. Dissolução de fitólitos do tipo halteres de capim Jaraguá (Hyparrhenia rufa), em doses crescentes de hidróxido de sódio à temperatura ambiente

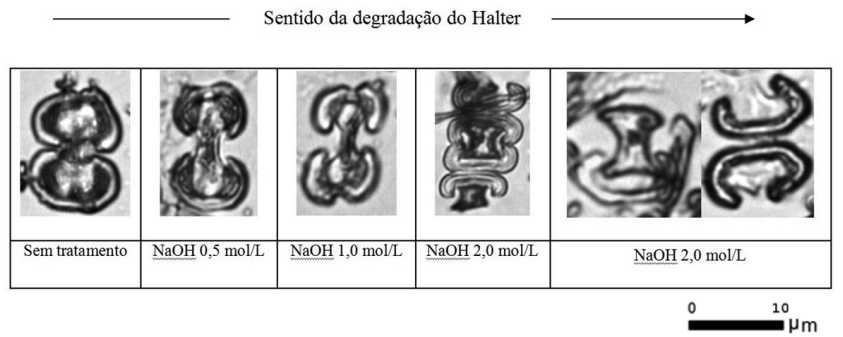

Figura 6. Dissolução de fitólitos do tipo halteres de capim Jaraguá (Hyparrhenia rufa), em doses crescentes de hidróxido de sódio em mufla a $90^{\circ} \mathrm{C}$

\section{CONCLUSÕES}

As análises químicas dos extratos obtidos pela reação do $\mathrm{NaOH}$ com os fitólitos não foram capazes de mostrar a relação direta da composição química com a estabilidade dos fitólitos. Contudo, os dados analíticos obtidos são úteis para conhecimento da química dos corpos silicosos.

Os fitólitos do capim Jaraguá contêm concentrações consideráveis de $\mathrm{Si}, \mathrm{Al}, \mathrm{Fe}, \mathrm{Mg}$ e P, além de concentrações menores de $\mathrm{Cu}, \mathrm{Cd}$ e Zn.

O desgaste dos fitólitos, especialmente dos halteres, observado ao microscópio óptico, foi eficiente para mostrar a sua instabilidade em meio básico. Este é um procedimento promissor para o estudo da estabilidade de corpos silicosos.

A estabilidade dos fitólitos em meio básico diferiu entre as formas e tamanhos dos mesmos, sendo que estômatos e tecidos silicificados se dissolveram juntamente com os halteres e entre estes, a dissolução foi mais ativa naqueles de tamanhos maiores.

\section{REFERÊNCIAS}

1. Lindsay, W. L.; Chemical equilibria in soils, Wiley-Interscience: New York, 1979.

2. Isaji, C.; Hydrobiologia 2003, 504, 31 .

3. Iler, R. K.; The colloid chemistry of silica and silicates, Cornell University Press: Ithaca, 1955.

4. Tréguer, P. C. R.; Geoscience 2002, 334, 3.

5. Epstein, E.; Proc. Natl. Acad. Sci. 1994, 91, 11.

6. Epstein, E.; Ann. Rev. Plant Physiol. Plant Mol. Biol. 1999, 50, 641.

7. Martinez Angel, J. D.; Pineda Vasquez, T. G.; Junkes, J. A.; Hotza, D.; Quim. Nova 2009, 32, 1110.

8. Exley, C.; J. Inorg. Biochem. 1998, 69, 139.

9. Meunier, J. D.; Comp. Rend. Geosci. 2003, 335, 1199.

10. Alexandre, A.; Meunier, J.-D.; Colin, F.; Koud, J.-M.; Geochim. Cosmochim. Acta 1997, 61, 677.

11. Hart, D. M.; Humphreys, G. S. Em Phytolith depth functions in surface regolith materials; Roach, I. C., ed.; Advances in Regolith, Cooperative Research Centre for Landscape Environments and Mineral Exploration (CRC LEME): Bentley, 2003.

12. Runge, F.; Rev. Paleobot. Palynol. 1999, 107, 23. 
13. Carnelli, A. L.; Madella, M.; Theurillat, J. P.; Ammann, B.; Am. J. Bot 2002, 89, 346.

14. Parr, J. F.; Sullivan, L. A.; Soil Biol. Biochem. 2005, 37, 117.

15. Sendulsky, T.; Labouriau, L. G.; An. Acad. Bras. Ci. 1966, 38, 159.

16. Cavalcante, P. B.; Botânica 1968, 30, 1.

17. Campos, A. C.; Labouriau, L. G.; Pesq. Agropec. Bras. 1969, 4, 143.

18. Korndörfer, G. H.; Datnoff, L. E.; Corrêa, G. F.; J. Plant Nutr. 1999, $22,93$.

19. Sillanpaa, M.; Trace elements in soils and agriculture, FAO/SIDA: Rome, 1972. (FAO. Soils Bulletin, 17).

20. Kabata-Pendias, A.; Pendias, H.; Trace elements in soils and plants, $3^{\text {rd }}$ ed., CRC: Boca Raton, 1985.

21. Alloway, B. J.; Heavy metals in soils, Blackie and Son: Glasgow, 1990.
22. Rolim Neto, F. C.; Schaefer, C. E. G. R.; Fernandes Filho, E. I.; Corrêa, M. M.; Costa, L. M.; Rev. Bras. Ciênc. Solo 2009, 33, 1795.

23. Brownlow, A.H .; Geochemistry, Prentice-Hall: Englewood Cliffs, 1979.

24. Amanuma, K.; Suzuki, K. T.; Toxicology 1987, 44, 321.

25. IARC Monogram Evaluating the Carcinogenic Risk to the Human, International Agency for Research on Cancer: Lyon, 1993, p. 58.

26. Gadd, G. M.; Experientia 1990, 46, 834.

27. Baker, D. E.; Chesnin, L.; Adv. Agron. 1975, 27, 305.

28. Moraghan, J. T.; Mascagni, J. R. Em Environmental and soil factors affecting micronutrient deficiencies and toxities; Mortvedt, J. J.; Giordano, P. M.; Lindsay, W. L., eds.; Soil Science Society of America: Madison, 1991. 